of the 'pseudoseizure' patient in the surgical setting.

Pseudoseizures are paroxysmal episodes that often resemble epileptic seizures, but are psychological in origin. Stressful situations such as surgery under local anaesthetic are well known potential triggers of these episodes.

A 58-year-old Iraqi lady attended the maxillofacial department for the routine extraction of a tooth under local anaesthetic. The extraction was carried out without incident.

Ten minutes post-extraction I was urgently called to see the patient who had collapsed in the hospital stairwell. On inspection the patient was lying on the floor moaning, crying and exhibiting bizarre asynchronous movements. Her vital signs remained normal as she waxed and waned between periods of lucid normality and paroxysmal seizures. The on-call anaesthetist was summoned and supportive care was given in the anaesthetic recovery area until the pseudoseizures had completely subsided.

Good awareness of how to manage a pseudoseizure is vital to the surgeon, particularly when operating under local anaesthetic. These events can be extremely stressful for the patient, the patient's family and the dentist. Noting risk factors such as a history of abuse or trauma, or previous 'bad reactions to local', and recognising clinical features that differentiate pseudoseizures from epileptic seizures is vital. If the seizure-like episode persists or worsens experienced help should be sought without delay.

B. Collard, S. Johnson, L. Cascarini, S. Lee London

Useful reading:

1. Haines J D. A case of pseudoseizures. South Med J 2005; 98: 122-123.

2. Bowman E S. Pseudoseizures. Psychiatr Clin North Am 1998; 21: 649-657.

3. Chabolla D R, Krahn LE, So E L, Rummans T A. Psychogenic nonepileptic seizures. Mayo Clin Proc 1996; 71: 493-500.

DOI: $10.1038 / s j . b d j .2010 .6$

\section{DURAPHAT SHORTAGE}

Sir, I am writing to express my concerns over the current shortage of Duraphat varnish and inform my colleagues of the information I have obtained.
We are all aware of the Department of Health Delivering better oral health evidence-based guidelines which recommend the application of fluoride varnish twice yearly for all young adults and children and four times yearly for high risk individuals (for example those with special needs, orthodontic appliances and those likely to develop caries). The shortage of Duraphat varnish is therefore of concern to those of us wishing to avoid compromising our prevention regimes.

In respect of this I have contacted Colgate who informed me that the current shortage in supply is due to the unavailability of one of the major ingredients of the varnish and that the company do not expect Duraphat to be available to practitioners until January 2010. Having searched the market I have found an alternative solution, Clinpro White Varnish from 3M ESPE, which contains $50 \mathrm{mg}$ of sodium fluoride per $\mathrm{ml}$. Clinpro White varnish is easy to apply, requires the teeth to be only toothbrushclean, is moisture and saliva-tolerant and has a pleasant mint taste. Please be aware of the recommended dosage which varies dependent on the patient's age. I hope this information is of use to practitioners.

S. Williams

By email

DOI: $10.1038 /$ sj.bdj.2010.7

\section{BEYOND THE TEETH}

Sir, the search for truth is behind all legitimate human endeavour. In our profession, the practitioner has to forever make clinical decisions based on a balance between acquired knowledge and the best evidence from research.

It was, therefore, enlightening to find these principles expressed in the letter from A. Toy (BDJ 2009; 207: 345-346). 'We have to understand that no research finding can be applied directly to the problem in front of us... We have to exercise the skill of professional artistry to balance the heart and head.' Both these concepts are contrary to current practice guidelines.

Interestingly, in the same issue, F. B. Naini writes (BDJ 2009; 207: 345) on the negative terminology of 'deaf and dumb' and states: 'The one true deafness, the incurable deafness, is that of the mind'. Perhaps we could serve our patients better if instead of blindly following the 'clinical correctness' of evidence-based dentistry, we employ in addition our clinical judgement based on the years of accumulated knowledge and experience.

We need to recognise the immense complexity of the stomatognathic system and its intimate relationship with the rest of the body. In particular, the dental occlusion and its relationship to head/neck posture and the healthy functioning of the rest of the body. Respiration, deglutition and jaw relationships must be considered when diagnosing and treating malocclusion. The research of early pioneers like Arnold Nove, who wrote on cervico-facial orthopaedia ${ }^{1}$ along with many others, has been largely ignored by mainstream orthodontists in favour of a more rigid reductionist viewpoint. The treatment of malocclusion should be based on a more comprehensive understanding of its cause. Simply rearranging the teeth, minus a few premolars, to provide an aesthetic dental improvement does not fulfil our responsibility as physicians of the stomatognathic system. The demands of evidence-based research means that anecdotal reports are not considered when formulating treatment principles. Simple classifications of malocclusion into dental and jaw relationships ignore the often subtle complexity of individual variations.

The inevitable compensations involving head posture, the effects on the cervical vertebrae, spinal column and pelvic alignment require the cooperation and interdisciplinary work of physical therapists (eg osteopaths) if a comprehensive and stable result is to be achieved.

As a profession, we need to look beyond the teeth and jaws and recognise our full responsibility and the enormous contribution we can make to the general health and functioning of the entire body.

\section{R. M. Dean} London

1. Nove A A. Cervico-facial orthopaedia. The Dental Record, February 1946.

DOI: 10.1038/sj.bdj.2010.8 